NBER WORKING PAPER SERIES

\title{
DISCOURAGING DEVIANT BEHAVIOR IN MONETARY ECONOMICS
}

\author{
Lawrence Christiano \\ Yuta Takahashi \\ Working Paper 24949 \\ http://www.nber.org/papers/w24949
NATIONAL BUREAU OF ECONOMIC RESEARCH
1050 Massachusetts Avenue
Cambridge, MA 02138
August 2018

We are grateful for conversations with Marco Bassetto, V.V. Chari, John Cochrane, Martin Eichenbaum, Patrick Kehoe, Emi Nakamura, Armen Nurbekyan and Jón Steinsson. Although discussions with these people helped us greatly to clarify our thoughts, they do not necessarily agree with the arguments described in this paper. The views expressed herein are those of the authors and do not necessarily reflect the views of the National Bureau of Economic Research.

At least one co-author has disclosed a financial relationship of potential relevance for this research. Further information is available online at http://www.nber.org/papers/w24949.ack

NBER working papers are circulated for discussion and comment purposes. They have not been peer-reviewed or been subject to the review by the NBER Board of Directors that accompanies official NBER publications.

(C) 2018 by Lawrence Christiano and Yuta Takahashi. All rights reserved. Short sections of text, not to exceed two paragraphs, may be quoted without explicit permission provided that full credit, including $\left({ }^{\circ}\right.$ notice, is given to the source. 
Discouraging Deviant Behavior in Monetary Economics

Lawrence Christiano and Yuta Takahashi

NBER Working Paper No. 24949

August 2018

JEL No. E5

\title{
$\underline{\text { ABSTRACT }}$
}

We consider a model in which monetary policy is governed by a Taylor rule. The model has a unique equilibrium near the steady state, but also has other equilibria. The introduction of a particular escape clause into monetary policy works like the Taylor principle to exclude the other equilibria. We reconcile our finding about the escape clause with the sharply different conclusion reached in Cochrane (2011). Atkeson et al. (2010) study a different version of the escape clause policy, but that version is fragile in that it lacks a crucial robustness property.

\author{
Lawrence Christiano \\ Department of Economics \\ Northwestern University \\ 2001 Sheridan Road \\ Evanston, IL 60208 \\ and NBER \\ 1-christiano@northwestern.edu \\ Yuta Takahashi \\ Graduate School of Economics \\ Hitotsubashi University \\ 2-1 Naka, Kunitachi, Tokyo \\ Japan \\ yuta.s.takahashi@gmail.com
}




\section{Introduction}

Monetary models are notorious for having multiple equilibria. The standard New Keynesian model, which assumes that fiscal policy is passive and monetary policy is set by a Taylor rule is no exception. By a Taylor rule, we mean an interest rate rule that satisfies the Taylor Principle (i.e., has a big coefficient on inflation). An influential sequence of papers shows that such monetary models have two steady states. In simpler models that allow for an analytic characterization of the global set of equilibria, it is found that there are deflation equilibria, hyperinflation equilibria, equilibria in which inflation exhibits cycles and even chaos (see Benhabib, et al. 2001b; 2001a; 2002a; 2002b) (BSGU).

The literature on the standard New Keynesian model has generally ignored the equilibrium multiplicity issue by focusing on the unique local-to-steady-state equilibrium. We refer to this equilibrium as the desired equilibrium because in many models that equilibrium is first best or nearly so. Critics correctly argue that until the multiplicity issue has a convincing resolution, the New Keynesian model cannot be thought of as a model that determines the price level or anything else. $^{1}$ We study one proposal for dealing with the multiplicity issue. ${ }^{2}$

The proposal that we consider, which was suggested by Benhabib et al. (2002a) and Christiano and Rostagno (2001), is studied in a particular model. ${ }^{3}$ Ideally, that model would be the New Keynesian model, but a global analysis of equilibrium in that model appears to be infeasible at this time. We require a model which has the flavor of the New Keynesian model, but is tractable. In addition, our conclusions contradict those reached in Cochrane (2011) and Atkeson et al. (2010). So, to highlight the reason for the difference in results, we work with a model that is comparable to theirs.

The proposal that we study is motivated by the observation in our model that the undesired equilibria associated with a Taylor rule in effect require the complicity of the government. For

\footnotetext{
${ }^{1}$ See, for example, Cochrane (2011).

${ }^{2}$ Perhaps the best known approach for addressing multiplicity is one based on learning. See Christiano et al. (2018a) and the extensive literature they cite.

${ }^{3}$ Both are related to the work of Obstfeld and Rogoff (1983) (see Obstfeld and Rogoff (2017)).
} 
example, the exploding hyperinflation equilibria that are possible under the Taylor rule can only happen if it is accommodated by exploding money growth. This observation suggests a simple modification to the Taylor rule: follow that rule as long as the economy remains in a neighborhood of the desired equilibrium and implement an escape clause in the event that a non-desired equilibrium appears to form. The escape clause could specify that if inflation moves outside a particular monitoring range, then the government deviates from the Taylor rule in favor of some other policy that directly moves inflation back into the monitoring range. ${ }^{4}$ The policy to which the government deviates under the escape clause might not be optimal in normal times, but the mere existence of the escape clause prevents undesired equilibria from forming in the first place. A policy in which the government has one set of rules in normal times, but is prepared to deviate to another set of rules under exigent circumstances is not unprecedented. For example, many governments which respect individual liberty in normal times have the authority to impose martial law, an entirely different regime, in the event of widespread disorder. ${ }^{5}$

Our discussion pushes back against the conclusions reached in Cochrane (2011) and in Atkeson et al. (2010) about the type of escape clause policy considered here. Cochrane (2011) agrees that the escape clause rules out the non-desired equilibria. However, he argues that it does so by a government commitment to do something infeasible (blow up the world) in case the undesired allocations occur. Cochrane (2011) argues, reasonably, that a policy that rules out equilibria by a blow-up-the-world threat is not economically interesting. This is because it is hard to imagine an actual government making such a commitment or private agents believing it. A problem with Cochrane (2011)'s argument is that he makes it within the framework of a standard equilibrium concept. That concept does not allow for off-equilibrium events such as the non-desired allocations. So, it is silent about the economic reason that such allocations are not chosen in equilibrium. We follow Bassetto (2005) and Atkeson et al. (2010) by defining the concept of a strategy equilibrium,

\footnotetext{
${ }^{4}$ Taylor $(1996$, p. 37) suggests a policy similar to our escape clause when he says "I would argue that interest rate rules need to be supplemented by money rules in cases of either extended deflation or hyperinflation."

${ }^{5}$ Other examples include the 'unusual and exigent circumstances' clause, section 13.3, in the Federal Reserve Act (see https://www.federalreserve.gov/aboutthefed/section13.htm) used to rationalize the use of unconventional monetary policy in the wake of the 2008 Financial Crisis. Another example is the exigent circumstances under which the Fourth Amendment to the US Constitution's prohibition against a Warrantless search and seizure may be ignored (see https://www.law.cornell.edu/wex/fourth_amendment).
} 
which makes it possible to study how it is that the escape clause excludes non-desired allocations. ${ }^{6}$

The strategy equilibrium extends the standard concept of equilibrium by opening up offequilibrium paths at each date. The question of why non-desired allocations are not equilibria is answered by asking the agents what it is about the escape clause that discourages them from deviating from the equilibrium path. Following Atkeson et al. (2010), we construct off-equilibrium paths by adopting the Dixit-Stiglitz production framework. Each intermediate good price setter chooses its price simultaneously and without coordinating. To decide what price to set, a price setter must form a conjecture about what prices the other agents choose and they must contemplate the associated continuation equilibrium for the economy. Thus, we can think of agents' choice of price as their best response to what others do. In a competitive equilibrium, they select a belief about what others do that corresponds to the fixed point of this best response function. For this view about belief formation to be interesting, we require that for each possible conjecture about what others do, there is a well defined continuation equilibrium. In addition, we require that there exists a fixed point. If either of these two requirements are not satisfied, then the problem of forming a belief about inflation is not well defined and we say that a strategy equilibrium does not exist. Note that even though the individual agents are atomistic, the way they arrive at their belief about current inflation requires strategic thinking. Hence, the reason for the name of our equilibrium concept.

The escape clause rules out inflation above the monitoring range because such an inflation rate is not a fixed point of the best response function. A firm that conjectures high inflation understands that the government will respond by raising the nominal interest rate sharply (that reflects the Taylor Principle) and lowering future inflation (that reflects the switch to low money growth). The resulting high real interest rate produces a recession in the model, which reduces marginal cost. Firms' best response is to post low prices, with the consequence that high inflation does not occur. In short, with the escape clause the government asserts that it is ready to engineer a Volcker-type recession in case inflation is high, and the private economy responds by setting prices

\footnotetext{
${ }^{6}$ Our equilibrium concept coincides with the 'sophisticated equilibrium' concept in Atkeson et al. (2010). We give ours a different name because the objects in our equilibrium are sequences rather than functions. Our choice of equilibrium concept is practical in our setting because we generally work with non-stochastic versions of our model. By working with sequences, we are able to minimize notation.
} 
so that high inflation does not happen. Deviations from the equilibrium path are discouraged without blow-up-the-world threats.

Why do we reach a conclusion so different from Cochrane (2011)'s? The answer lies in his assumption of an endowment economy. That assumption cuts the heart out of the mechanism by which the escape clause does its work in our model. The fall in output and rise in the real interest rate that occurs in our model is impossible in an endowment economy. We reproduce Cochrane (2011)'s blow-up-the-world result in the endowment economy version of our model by showing that continuation equilibria do not exist for non-fixed point inflation conjectures (that is, that economy does not have a strategy equilibrium). So, we agree that the escape clause works by a blow-up-the-world threat in Cochrane (2011)'s model. But, his result does not generalize to a production economy. We conclude that Cochrane (2011)'s analysis says nothing about the properties of standard macroeconomic models.

We then consider Atkeson et al. (2010). Their primary economic conclusion is that a key tenet of the New Keynesian canon - that the Taylor principle is a necessary ingredient of good monetary policy - is false. They endorse the escape clause, but propose shrinking the monitoring range for inflation to a singleton that only includes the desired inflation rate. The desired equilibrium is indeed uniquely implemented by their policy and, as they emphasize, the size of the coefficient on inflation in the Taylor rule plays no role in ensuring that inflation remains at its desired level. We make two observations on Atkeson et al. (2010). First, the way that the escape clause works is very much in the spirit of the Taylor Principle. The idea behind the Taylor Principle is that with the big coefficient on inflation, a rise in inflation produces a rise in the real interest rate and, by slowing down the economy, that brings inflation back down to its desired level (see Taylor (1999, p.325)'s discussion of 'leaning against the wind'). That stabilizing force works reasonably well in a New Keynesian model in a neighborhood of the model steady state, but it does not exclude equilibria with inflation far from steady state. As explained above, the escape clause excludes those equilibria by a mechanism very similar to the way the Taylor Principle works near steady state. ${ }^{7}$ So, Atkeson

\footnotetext{
${ }^{7}$ How the Taylor Principle works near steady state is well understood. We briefly review that here for completeness. Consider the standard New Keynesian model without capital, linearized around the first-best equilibrium. The IS curve is $x_{t}=E_{t} x_{t+1}-\left[r_{t}-E_{t} \pi_{t+1}-r_{t}^{*}\right]$, where $x_{t}$ denotes the log difference between output in the equilibrium with the Taylor rule and first-best output. The Taylor rule is $r_{t}=\phi \pi_{t}$, where $\phi>1$. The Phillips curve is
} 
et al. (2010)'s conclusion that the Taylor Principle is not necessary for unique implementation of the close-to-steady-state equilibrium is misleading, at least when viewed through the eyes of our model. ${ }^{8}$

Second, we show that the Atkeson et al. (2010) analysis is fragile. If a vanishingly small number of price setters make vanishingly small mistakes (i.e., trembles) the monitoring range would be violated by accident and not because an undesired equilibrium is forming. Yet, the Atkeson et al. (2010) policy would respond by shifting to the money growth regime. This regime-shift could induce a substantial drop in welfare if there are shocks to money demand.

Atkeson et al. (2010) report that the good performance of their monetary policy is robust to trembles, in contrast to the conclusion reached here. Their conclusion reflects that they linearize the map from individual intermediate good prices to the aggregate price index (see Atkeson et al. (2010, p. 53)). By the law of large numbers, zero-mean trembles are wiped out in that linear representation. But, our analysis works with the actual nonlinear mapping, in which trembles do matter for Jensen's inequality reasons. This is why we conclude that Atkeson et al. (2010)'s finding that their policy uniquely supports the desired equilibrium is not robust to trembles. Our policy, which adopts a wide monitoring range for inflation and the Taylor principle, uniquely implements the desired equilibrium and is robust to trembles.

Section 2 sets up our model economy and shows that a model with a Taylor rule has a continuum of equilibria. We include this well-known result here so that our analysis is self-contained. ${ }^{9}$ Section $\pi_{t}=\beta E_{t} \pi_{t+1}+\kappa x_{t}$, where $\kappa>0$ and $\beta \in(0,1)$. Finally, $r_{t}^{*}$ denotes the natural rate of interest, $r_{t}^{*}=E_{t} a_{t+1}-a_{t}$ and $a_{t}$ denotes a shock to technology. Suppose that the shock has the representation, $\Delta a_{t}=\rho \Delta a_{t-1}+\varepsilon_{t}$, where $\Delta a_{t}=a_{t}-a_{t-1}, \rho \in[0,1)$ and $\varepsilon_{t}$ is an iid shock. It is easy to verify that the locally unique equilibrium has the form:

$$
r_{t}-E_{t} \pi_{t+1}=\psi \Delta a_{t}, \quad x_{t}=\frac{(1-\beta \rho)}{\kappa(\phi-\rho)} \psi \Delta a_{t}, \quad \pi_{t}=\frac{\psi}{\phi-\rho} \Delta a_{t}
$$

where $\psi \equiv \rho\left[\frac{(1-\beta \rho)(1-\rho)}{\kappa(\phi-\rho)}+1\right]^{-1}$. For $\phi$ sufficiently large, $\psi$ is close to $\rho$ and $r_{t}-E_{t} \pi_{t+1} \simeq r_{t}^{*}, \pi_{t} \simeq 0$ and $x_{t} \simeq 0$. So, a big value of $\phi$ stabilizes the equilibrium around first best and this is accomplished by the operation of the Taylor principle (i.e., the real rate of interest increases when inflation is high because $\psi>0$ and $\phi>\rho$ ). It is easy to verify that this result also holds when the technology process is replaced by $a_{t}=\rho a_{t-1}+\varepsilon_{t}$ or when the shock is instead a stationary disturbance to labor supply.

${ }^{8}$ We do not mean to suggest that the Taylor principle is desirable in all possible models. For example, in Christiano et al. (2010b) and Christiano (2016) it is shown that if the working capital channel is strong enough, then the Taylor principle could be destabilizing. Christiano et al. (2010a) explain how the Taylor principle could inadvertently trigger a stock market boom in response to news about the future.

${ }^{9}$ See BSGU, as well as Woodford (2003). 
3 shows how the introduction of a monitoring range for inflation and an escape clause renders the equilibrium unique. We explain Cochrane (2011)'s blowing-up-the-world critique of this uniqueness result. Section 4 defines a strategy equilibrium. We establish that our model has a strategy equilibrium, and that the desired equilibrium is uniquely implemented by the escape clause. We describe the key steps in the proof, but we move details to Appendix B. Section 5 reconciles our findings about the escape clause with Cochrane (2011)'s critique. Section 6 addresses Atkeson et al. (2010)'s conclusion that the Taylor Principle is not necessary to uniquely implement the desired equilibrium. We also explain the lack of robustness of their version of the escape clause to trembles. Finally, section 7 offers a brief conclusion.

\section{Model With Taylor Rule and No Escape Clause}

The model we work with is in some ways standard. We use the household preferences and DixitStiglitz production structure used in the New Keynesian literature. For now, we assume flexible prices, though in later sections we adopt the simple model of price stickiness based on a timing assumption relative to shocks suggested in Christiano et al. (1997). For the purpose of our analysis, it is necessary to be explicit about the demand for money. We select our model for tractability and to maximize comparability with the models in Cochrane (2011) and Atkeson et al. (2010).

The government provides monetary transfers to households:

$$
\left(\bar{\mu}_{t}-1\right) \bar{M}_{t-1}, \quad \bar{\mu}_{t}=\bar{M}_{t} / \bar{M}_{t-1},
$$

where $\bar{M}_{t}$ denotes the end-of-period-stock of money and $\bar{\mu}_{t}$ denotes the money growth rate, a variable controlled directly by the government. The government levies sufficient lump sum taxes that, given the money growth rate, the government's budget is balanced in each period. ${ }^{10}$

Monetary policy policy selects a sequence, $\left\{\bar{\mu}_{t}\right\}_{t=0}^{\infty}$, so that, in equilibrium,

\footnotetext{
${ }^{10} \mathrm{~A}$ number of interesting issues concerning fiscal policy are left out of the analysis. For example, a property of our model is that non-negative money growth rate rules out a zero interest rate equilibrium. In the presence of government debt, this result is not necessarily true. For further discussion and a defense of the position taken here, see Christiano and Rostagno (2001, section 2.4).
} 


$$
\bar{R}_{t}=\max \left\{1, \bar{R}^{*}\left(\frac{\bar{\pi}_{t}}{\bar{\pi}^{*}}\right)^{\phi}\right\}, \quad \bar{\pi}_{t+1} \equiv \frac{P_{t+1}}{P_{t}}, \quad \bar{R}^{*} \equiv \bar{\pi}^{*} / \beta,
$$

where $\bar{\pi}^{*} \geq 1$ and $\bar{R}^{*}$ are the desired inflation and interest rate. Here, we assume that $\phi>1$. Finally, $\beta \in(0,1)$, denotes the representative household's discount rate.

The representative household's problem is:

$$
\begin{array}{ll}
\max _{\left\{c_{t}, l_{t}, m_{t}, b_{t}\right\}_{t=0}^{\infty}} & \sum_{t=0}^{\infty} \beta^{t}\left[\frac{c_{t}^{1-\gamma}}{1-\gamma}-\frac{l_{t}^{1+\psi}}{1+\psi}\right], \quad \gamma>1, \psi>0 \\
\text { s.t. } \quad & m_{t}+b_{t} \leq W_{t} l_{t}+m_{t-1}-P_{t-1} c_{t-1}+\bar{R}_{t-1} b_{t-1}+T_{t} \\
& P_{t} c_{t} \leq m_{t} \\
& \left(m_{-1}-P_{-1} c_{-1}+R_{-1} b_{-1}\right) \text { given. }
\end{array}
$$

Here, $c_{t}$ and $l_{t}$ denote consumption and employment; and $m_{t}$ and $b_{t}$ denote the household's endof-period- $t$ stock of money and one-period bonds. Note that the household has a cash constraint which requires that its end-of-period $t$ cash balances be sufficient to cover its period $t$ consumption expenditures. The term on the left of the equality in the first constraint on the household problem describes the allocation of the household's end-of-period financial resources between cash and bonds. The household sources of financial resources are: cash accumulated by working, $W_{t} l_{t}$, excess cash carried over from the previous period, $m_{t-1}-P_{t-1} c_{t-1}$, interest earned on the previous period's bond holdings, $\bar{R}_{t-1} b_{t-1}$, and lump sum transfers from taxes, money transfers and profits, $T_{t}$. The second constraint is the household cash constraint.

The first order necessary and sufficient conditions for household optimization are 


$$
\begin{aligned}
\frac{W_{t}}{P_{t}} & =c_{t}^{\gamma} l_{t}^{\psi}, \\
c_{t}^{-\gamma} & =\beta c_{t+1}^{-\gamma} \frac{\bar{R}_{t}}{\bar{\pi}_{t+1}}, \\
0 & =\left(R_{t}-1\right)\left[m_{t}-P_{t} c_{t}\right], \quad m_{t} \geq P_{t} c_{t}, \\
m_{t}+b_{t} & =W_{t} l_{t}+m_{t-1}-P_{t-1} c_{t-1}+\bar{R}_{t-1} b_{t-1}+T_{t}, \\
0 & =\lim _{T \rightarrow \infty} \beta^{T} u^{\prime}\left(c_{T}\right) \frac{m_{T}-P_{T} c_{T}+b_{T}}{P_{T}} .
\end{aligned}
$$

Sufficiency and necessity of these conditions, as well as assumptions required to ensure boundedness of the household's intertemporal consumption opportunity set, are established in Christiano and Takahashi (2018).

A final output good is produced by a competitive, representative firm using the following production function:

$$
Y_{t}=\left[\int_{0}^{1} Y_{i, t}^{\frac{\varepsilon-1}{\varepsilon}} d i\right]^{\frac{\varepsilon}{\varepsilon-1}}, \quad \varepsilon>1
$$

The firm takes the price output, $P_{t}$, and the prices of the inputs, $p_{i, t}, i \in[0,1]$ as given. The first order conditions associated with its profit maximization is:

$$
Y_{i, t}=Y_{t}\left(\frac{p_{i, t}}{P_{t}}\right)^{-\varepsilon}
$$

for $i \in[0,1]$. The first order conditions, together with the production function, impose a restriction across the aggregate price index and the price of intermediate goods:

$$
P_{t}=\left[\int_{0}^{1} p_{i, t}^{1-\varepsilon} d i\right]^{\frac{1}{1-\varepsilon}} .
$$

The $i^{\text {th }}$ intermediate good, $Y_{i, t}$, is produced by a monopolist with the following production function:

$$
Y_{i, t}=l_{i, t}
$$


Here, $l_{i, t}$ denotes the labor input employed by the $i^{\text {th }}$ firm. In the usual way, the $i^{\text {th }}$ firm sets its price as a markup over its marginal cost, $W_{t}$ :

$$
p_{i, t}=\frac{\varepsilon}{\varepsilon-1}(1-\tau) W_{t}=W_{t}
$$

where $\tau$ denotes a government subsidy, which we assume cancels the markup. With all intermediate good firms setting the same price, we have that

$$
P_{t}=W_{t}
$$

The goods, labor, money and bond market clearing conditions are:

$$
c_{t}=Y_{t}, \quad \int_{0}^{1} l_{i, t}=l_{t}, \quad \bar{M}_{t}=m_{t}, \quad b_{t}=0 .
$$

Let

$$
\bar{a}_{t}=\left(l_{t},\left\{l_{i, t}\right\}_{i \in[0,1]},\left\{p_{i, t}\right\}_{i \in[0,1]}, c_{t}, \bar{\pi}_{t}, \bar{R}_{t}, W_{t}, \bar{\mu}_{t}, \bar{M}_{t}, m_{t}, b_{t}\right)
$$

Collecting the equilibrium conditions, we now define a monopolistically competitive equilibrium. We simplify the name to simply 'competitive equilibrium':

Definition 1. A competitive equilibrium under the Taylor rule is a sequence, $\left(\bar{a}_{t}\right)_{t=0}^{\infty}$, that satisfies, for $t \geq 0$, (i) intermediate good firm optimality, (2.12); (ii) final good firm optimality, (2.9)(2.11); (iii) household optimization, (2.4)-(2.8), conditional on $m_{-1}-P_{-1} c_{-1}+R_{-1} b_{-1}, P_{-1}$; (iv) government policy, (2.1)-(2.2), and (v) market clearing, (2.14).

We define competitive equilibria under other monetary policy rules by suitable adjustment to condition (iv).

We now obtain a dynamic equation that can be used to identify all the equilibria in our model. We constructed our model so that equation is identical to the equation that characterizes the equilibria in Cochrane (2011)'s model. We will exploit this fact below. The similarity is completed by scaling and the logging the variables. 
Combining (2.13) and (2.14), we obtain:

$$
1=c_{t}^{\gamma} l_{t}^{\psi}=c_{t}^{\psi+\gamma}
$$

so that for all $t \geq 0$,

$$
c_{t}=1
$$

As a result, the intertemporal Euler equation reduces to the Fisher equation:

$$
R_{t}=\pi_{t+1}
$$

where $R_{t}=\ln \left(\bar{R}_{t} / \bar{R}^{*}\right), \pi_{t+1}=\ln \left(\bar{\pi}_{t} / \bar{\mu}^{*}\right)$.We can also express the monetary policy rule in scaled and logged form:

$$
R_{t}=\max \left\{R^{l}, \phi \pi_{t}\right\}
$$

where $R^{l} \equiv \ln \left(1 / \bar{R}^{*}\right)$. It is also useful to define the scaled and logged money growth rate:

$$
\mu_{t} \equiv \ln \left(\frac{\bar{\mu}_{t}}{\bar{\mu}^{*}}\right)
$$

Combining (2.17) and (2.18) we obtain:

$$
\pi_{t+1}=\max \left\{R^{l}, \phi \pi_{t}\right\}
$$

Also, the transversality condition, taking into account (2.14) and (2.16), corresponds to:

$$
\lim _{T \rightarrow \infty} \beta^{T} \frac{M_{T}}{P_{T}}=0
$$

Equation (2.20) is useful for studying the equilibria in the model for the following reason:

Proposition 1. For any sequence, $\left(\pi_{t}\right)_{t=0}^{\infty}$ that satisfies the difference equation, (2.20), it is possible to construct the other equilibrium variables in such a way that all the conditions for a competitive equilibrium are satisfied. 
For the proof, see Appendix A.1.

Figure 2.1: Fisher Equation and Taylor Rule

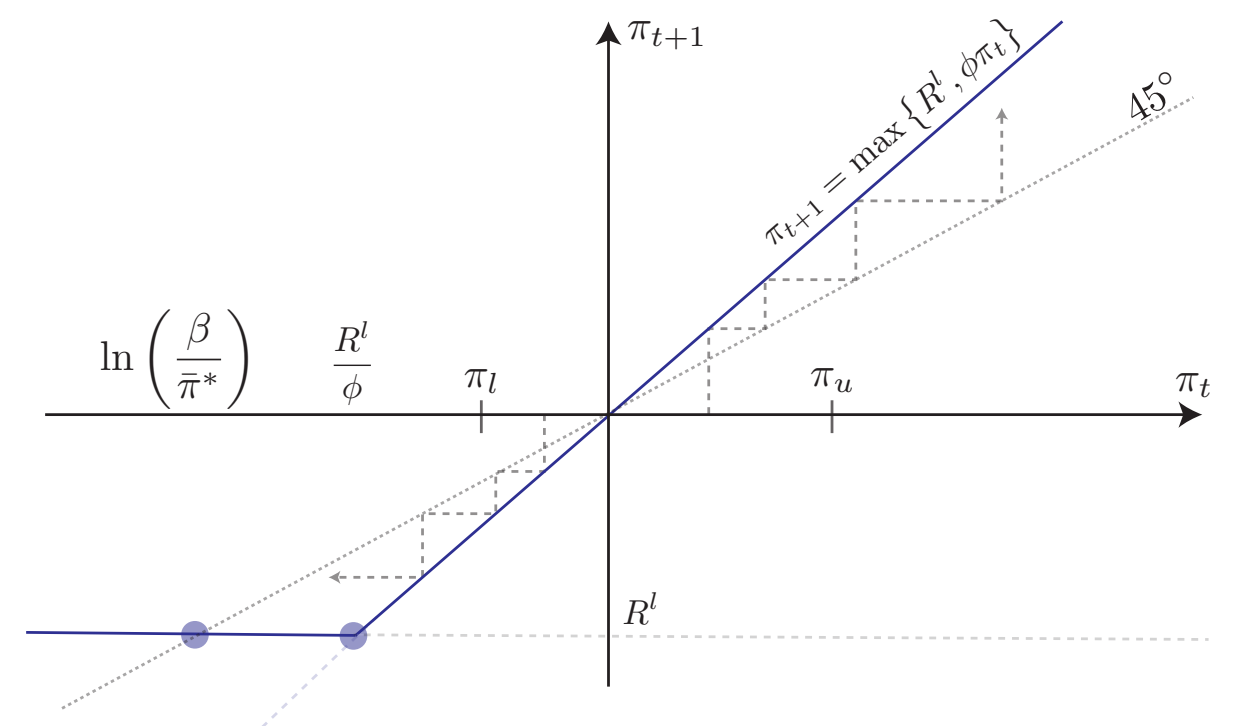

Figure 2.1, a variant on the well-known figure in Benhabib et al. (2001b, Fig. 1), graphs $(2.20) .{ }^{11}$ From this figure it is easy to see that the model has many equilibria, each indexed by the value of $\pi_{0}$. The desired equilibrium corresponds to $\pi_{t}=0$ for $t \geq 0$. Consider the two inflation rates marked in Figure 2.1 by $\pi_{l}$ and $\pi_{u}$. We refer to this interval as the inflation monitoring range. Note that, due to the high value of $\phi$, there is exactly one equilibrium in which inflation is always in the monitoring range, $\pi_{t} \in\left[\pi_{l}, \pi_{u}\right]$ for $t \geq 0$. The allocations in that equilibrium correspond to the desired equilibrium. This observation plays an important role in the analysis below.

The economic interpretation of (2.20) plays an important role in our analysis. According to Woodford (2003, p. 128), “...the equation indicates how the equilibrium inflation rate in period $t$ is determined by expectations regarding inflation in the following period." Thus, an exploding inflation equilibrium is caused by high expected inflation. F'or example, it is not caused by a $\pi_{0}$ different from zero. According to Woodford (2003, p. 128), 'Such reasoning involves a serious misunderstanding of the causal logic of the difference equation [(2.20)].' So, to exclude non-desired equilibria, policy must discourage agents from expecting non-desired levels of inflation.

\footnotetext{
${ }^{11}$ For an extended discussion see, for example, Woodford (2003, Chapter 2, section 4, p. 123). This figure plays an important role throughout our analysis and so we include it here for completeness.
} 


\section{Model With Escape Clause}

The fact that the unique equilibrium with $\pi_{t} \in\left[\pi_{l}, \pi_{u}\right]$ is the desired equilibrium for all $t \geq 0$ is an important motivation for the following policy:

Definition 2. Taylor rule with an escape clause: if $\pi_{s} \in\left[\pi_{l}, \pi_{u}\right]$, for $s=0, \ldots, t-1$ follow the Taylor rule, (2.18), with $\phi>1$ in period $t$. Otherwise, set (scaled) money growth, $\mu_{t}$, to a constant, $\mu \in\left[\mu_{l}, \mu_{u}\right]$. Here, $\mu_{u}=\pi_{u}$ and $\mu_{l}=\max \left\{\pi_{l}, \log \frac{1}{\bar{\mu}^{*}}\right\}$. Also,

$$
\phi^{-1} R^{l}<\pi_{l} \leq 0 \leq \pi_{u}<\infty
$$

The lower bound on the range, $\left[\mu_{l}, \mu_{u}\right]$, is designed to guarantee that unscaled money growth under the escape clause, $\bar{\mu}$, is no less than unity. This helps to ensure uniqueness of equilibrium under constant money growth. ${ }^{12}$ The lower bound on the monitoring range excludes inflation rates that imply the zero lower bound on the interest rate is binding. This assumption is simply made for analytic convenience.

A competitive equilibrium under a Taylor rule with an escape clause is unique and it is the desired equilibrium. This result is established in three steps. First, we establish that the constant money growth rate under the escape clause has a unique equilibrium:

Lemma 1. Suppose $\bar{M}_{-1}$ is given and monetary policy sets $\bar{M}_{t}=\bar{\mu} \bar{M}_{t-1}$ for $t \geq 0$, where $\bar{\mu} \geq 1$. There exists a unique competitive equilibrium with the properties:

$$
\bar{R}_{t}=\beta^{-1} \bar{\mu}>1, \quad c_{t}=1, \quad \bar{\pi}_{t+1}=\bar{\mu}, \quad \text { for } \quad t \geq 0, \quad \text { and } \quad P_{0}=\bar{M}_{-1} \bar{\mu} .
$$

For the proof, see Appendix A.2.

If Lemma 1 were not true and an equilibrium did not exist, it would be impossible to meaningfully ask what would happen if $\pi_{t} \notin\left[\pi_{l}, \pi_{u}\right]$, because agents would not know how to form expectations about $t+1 .^{13}$ The second step shows that there is no competitive equilibrium in which $\pi_{t} \notin\left[\pi_{l}, \pi_{u}\right]$ :

Lemma 2. Consider the case in which monetary policy is the Taylor rule with the escape clause. An equilibrium has the following property: $\pi_{t} \in\left[\pi_{l}, \pi_{u}\right]$ for $t \geq 0$.

\footnotetext{
${ }^{12}$ To see how multiplicity of equilibria can arise when money growth lies between $\beta$ and unity, see Albanesi et al. (2003, Proposition 4).

${ }^{13}$ For our analysis it is convenient that we have a unique equilibrium under constant money growth, but we have not investigated whether uniqueness is necessary for our conclusions.
} 
This Lemma lies at the heart of our equilibrium uniqueness result. So, we include the proof here:

Proof. Suppose not, and that there exists an equilibrium with $\pi_{T} \notin\left[\pi_{l}, \pi_{u}\right]$ where $T$ is the first date in which the monitoring range is violated. Consider the case, $\pi_{T}>\pi_{u}$. The Taylor rule implies $R_{T}=\phi \pi_{T}>\pi_{u}$. The escape clause and Lemma 1 imply $\pi_{T+1}=\mu \leq \pi_{u}$, so that

$$
R_{T}-\pi_{T+1}>0
$$

violating the Fisher equation, (2.17). This contradicts the assumption of equilibrium.

Next, consider the case $\pi_{T}<\pi_{l}$. Then, $R_{T}=\max \left\{R^{l}, \phi \pi_{T}\right\} \leq 0$. But, $R^{l}<\phi \pi_{l}<\pi_{l}$, so $R_{T}<\pi_{l}$. Also, $\pi_{T+1}=\mu \geq \pi_{l}$, so that

$$
R_{T}-\pi_{T+1}<0
$$

violating the Fisher equation, (2.17). This contradicts the assumption of equilibrium. This establishes the result sought.

The third step is the main proposition:

Proposition 2. Suppose monetary policy is governed by the Taylor rule with an escape clause. The only equilibrium is the desired equilibrium.

The result is not surprising, given Lemma 2 and Figure 2.1. The former says that there is no equilibrium with $\pi_{t} \notin\left[\pi_{l}, \pi_{u}\right]$. The latter indicates that the only equilibrium with $\pi_{t} \in\left[\pi_{l}, \pi_{u}\right]$ is $\pi_{t}=0$ for all $t$. For a formal proof, see Appendix A.3.

Cochrane (2011) maintains that the uniqueness result in Proposition 2 is correct, but uninteresting in an economic sense. As we noted at the end of Section 2, the non-desired equilibria in the model are caused by high or low expectations about future inflation, so that to exclude those equilibria requires preventing such expectations from being formed. According to Cochrane (2011) the escape clause prevents such expectations by committing to do something infeasible (i.e., violate $\left.R_{T}-\pi_{T+1}=0\right)$ in case those expectations are realized. We agree that a model in which policy 
works in this way is not interesting. Actual agents would presumably not believe government commitments to do infeasible things. Moreover, it is hard to imagine any government announcing such a policy in the first place.

\section{Unique Implementation of the Desired Equilibrium With- out Blowing up the World}

We know from Proposition 2 that the escape clause rules out non-desired equilibria. In this section we describe an equilibrium concept that allows us to understand how it rules out equilibria. The standard concept of equilibrium permits us to ask the agents in the model a narrow range of questions: 'why did you choose to work this level of hours rather than that level?', or 'why did you set a low price rather than a high price?'. Within the standard concept of equilibrium agents take the broader environment, the aggregate price level, aggregate output, etc., as given. We cannot ask them 'big picture' questions such as, 'what is it about government policy that makes you think hyperinflation will not occur?'. This type of question is necessarily about what would happen if the economy went off the equilibrium path. Attempts have been made to study what might happen off the equilibrium path simply by studying the equations that hold in a competitive equilibrium (see Cochrane (2011)). However, this sort of inference can go seriously wrong. As we show below, our model offers a stark illustration of this point.

The alternative concept of equilibrium that we use here was first advocated in macroeconomics by Bassetto (2005). Bassetto (2005)'s framework applies in a situation like ours, in which the government has full commitment to implement its policy rule and we want to understand the

economic reason that that policy rule excludes equilibria. Atkeson et al. (2010) systemize the approach by exploiting conceptual similarities between the framework used here and the framework developed in Chari and Kehoe (1990) to think about equilibrium when the government lacks the ability to commit.

To integrate off-equilibrium allocations into the analysis, we must, in effect, build exit-ramps from the equilibrium path. In principle, that could be done in a variety of ways. For the purpose 
of comparison, we adopt the approach in Atkeson et al. (2010). This involves taking a closer look at the intermediate good firms' pricing decision. We do this in the first subsection below. Section 4.2 discusses the formation of firm beliefs, a feature of our model that plays a central role in the analysis. Section 4.3 discusses the definition of a strategy equilibrium. The last two sections discuss how high and moderate inflation equilibria are ruled out in the strategy equilibrium of our model. Other cases are studied in Appendix B.

\subsection{Sequence of Events During the Period}

In our discussion of the model in Section 2 we assumed that the $i^{\text {th }}$ firm knows the wage, $W_{t}$, at the time it sets its price, $p_{i, t}$ (see (2.12)). But, this assumption is problematic. The nominal wage rate, $W_{t}$, is determined in markets simultaneously with other variables like $P_{t}$. We assume that the intermediate good firms set their price simultaneously and without knowing what the other firms are doing. Under these circumstances, it is logically impossible for the $i^{\text {th }}$ firm to actually observe $P_{t}$ when it sets its own price, $p_{i, t}$. The reason is that by $(2.11), P_{t}$ is the consequence of the prices set by intermediate good firms. Obviously, firms cannot see the consequences of their actions until after their actions have been taken.

Motivated by the preceding observation, we assume that $p_{i, t}$ is set before $W_{t}$ is realized. To capture this observation, we divide each period $t$ into two parts: morning and afternoon. Intermediate good firms set their prices, $\left\{p_{i, t}\right\}_{i \in[0,1]}$, in the morning. In the afternoon, the intermediate good firm prices are taken as given and are part of the state of the economy. Conditional on this state, a period $t$ continuation equilibrium unfolds. We provide a formal definition of this equilibrium concept in Section 4.3 below. This is a sequence of markets equilibrium that starts in the afternoon of period $t$ and continues into all future periods.

\subsection{Best Response Function, Fixed Point and Beliefs}

We begin this section by focussing on the price-setting problem of an intermediate good firm. The second subsection below aggregates across the firms. 


\subsubsection{The Problem of the Individual Intermediate Good Firm}

In the morning of period $t$, the $i^{t h}$ intermediate good firm sets its price, $p_{i, t}$, as follows:

$$
p_{i, t}=W_{i, t}^{e}
$$

Here, the superscript, $e$, indicates the firm's conjecture about the value that a variable (in this case, $W_{t}$ ) will take on in the afternoon, as part of firm $i$ 's conjecture about the period $t$ continuation equilibrium. As noted in Section (4.3) below, the economic state in this continuation equilibrium includes, among other things, the prices set by all the other intermediate good firms, $\left\{p_{j, t}\right\}_{j \neq i}$. Thus, to set its price, the $i^{\text {th }}$ firm must form a conjecture about what the other intermediate good firms are doing.

We simplify the situation of the $i^{\text {th }}$ firm by adopting the following assumption:

Assumption 1. Intermediate good firm $i$ 's conjecture, $\left\{p_{j, t}^{e}\right\}_{j \neq i}$, about what other firms do is characterized by symmetry: $p_{j, t}^{e}=p_{j^{\prime}, t}^{e}$ for all $j, j^{\prime} \neq i$. We denote $p_{-i, t}^{e} \equiv p_{j, t}^{e}$.

Given symmetry a conjecture, $p_{-i, t}^{e}$, maps trivially (see (2.11)) into a conjecture about the aggregate price index that will be realized in the afternoon as part of the time $t$ continuation equilibrium. So, with a slight abuse of notation, we also denote the conjectured aggregate price index by $p_{-i, t}^{e}$. The $i^{t h}$ firm's conjecture about the nominal wage, $W_{i, t}^{e}$, is given by

$$
W_{i, t}^{e}=p_{-i, t}^{e}\left(\frac{W_{i, t}^{e}}{p_{-i, t}^{e}}\right)=p_{-i, t}^{e}\left(c_{i, t}^{e}\right)^{\gamma}\left(l_{i, t}^{e}\right)^{\psi}=p_{-i, t}^{e}\left(c_{i, t}^{e}\right)^{\gamma+\psi}
$$

In addition to (2.11), we have taken into account the intra-temporal equilibrium condition for labor, (2.4), that must hold in the afternoon. We have also used the fact that $c_{t}=l_{t}$ in the time $t$ continuation equilibrium. The object, $c_{i, t}^{e}$, is the $i^{t h}$ firm's conjecture about time $t$ aggregate consumption in the time $t$ continuation equilibrium. That is not a trivial object to compute, since households are forward looking and we turn to that issue below.

Substituting (4.2) into (4.1), we obtain an expression for the $i^{\text {th }}$ firm's price decision:

$$
p_{i, t}=p_{-i, t}^{e}\left(c_{i, t}^{e}\right)^{\gamma+\psi}
$$


To summarize, the logic underlying (4.3) is as follows. The $i^{\text {th }}$ firm forms a conjecture about what other firms do, $p_{-i, t}^{e}$. Treating $p_{-i, t}^{e}$ (and the history of the economy, which we discuss below) as the conjectured state, the firm then derives its conjecture about the entire time $t$ continuation equilibrium. The object on the right side of (4.3) represents the time $t$ market-clearing nominal wage rate in that equilibrium. So, (4.3) expresses the $i^{\text {th }}$ firm's price decision as a function of $p_{-i, t}^{e}$ and the relevant past history.

It is convenient to scale $(4.3)$ by $P_{t-1} \bar{\mu}^{*}$ and take logs:

$$
x_{i, t}=\pi_{i, t}^{e}+(\gamma+\psi) \ln c_{i, t}^{e}
$$

where $x_{i, t}$ and $\pi_{i, t}^{e}$ are given by:

$$
x_{i, t}=\ln \left(\frac{p_{i, t}}{P_{t-1} \bar{\mu}^{*}}\right), \quad \pi_{i, t}^{e}=\ln \left(\frac{p_{-i, t}^{e}}{P_{t-1} \bar{\mu}^{*}}\right)
$$

\subsubsection{Aggregating Across Firms}

The large amount of symmetry in the Dixit-Stiglitz environment motivates an additional assumption which facilitates aggregation:

Assumption 2. All intermediate firms form the same conjecture, so that $p_{-i, t}^{e}=p_{-j, t}^{e} \equiv p_{t}^{e}$ for all $i, j$.

Under Assumption 2, we can delete the $i$ index from the variables in (4.4) and refer to that expression as the best response of the 'representative intermediate good firm'.

We now provide a formal definition of a time $t$ continuation equilibrium. We denote a time $t-1$ history, $h_{t-1}$, as follows:

$$
h_{t-1}= \begin{cases}\left(m_{-1}-P_{-1} c_{-1}+R_{-1} b_{-1}, P_{-1}, \bar{M}_{-1}\right) & t=0 \\ \left(h_{t-2}, a_{t-1}\right) & t \geq 1\end{cases}
$$


where $a_{t}$ is the scaled and logged version of $\bar{a}_{t}$ defined in (2.15):

$$
a_{t}=\left(l_{t},\left\{l_{i, t}\right\}_{i \in[0,1]}, \pi_{t}^{e}, c_{t}, \pi_{t}, R_{t}, W_{t}, \mu_{t}, \bar{M}_{t}, m_{t}, b_{t}\right)
$$

Here, $\left\{p_{i, t}\right\}_{i \in[0,1]}$ in $\bar{a}_{t}$ has been replaced by $\pi_{t}^{e}$. Also, $\bar{R}_{t}$ in $\bar{a}_{t}$ has been replaced by $R_{t}$. Finally, $\pi_{t}$ and $\mu_{t}$ denote scaled and logged inflation and money growth. Past history, $h_{t-1}$, matters in this model in part because of the nature of monetary policy. For example, if $\pi_{j} \in\left[\pi_{l}, \pi_{u}\right]$ for all $j \leq t-1$, then monetary policy in period $t$ is the Taylor rule. Otherwise, it is a constant money growth rule.

We define:

Definition 3. A time $t$ continuation equilibrium conditional on $\left(h_{t-1}, \pi_{t}^{e}\right)$ is a sequence, $\left(a_{t+s}\right)_{s=0}^{\infty}$, that satisfies all the date $t+s, s \geq 0$ competitive equilibrium conditions (see Definition 1), with one exception. The exception is the period $t$ optimality condition for the intermediate good firm, $(2.12)$.

Consistent with our discussion about the trivial relationship between the aggregate price index and $p_{-i, t}^{e}$, time $t$ inflation in the continuation equilibrium, $\pi_{t}$, is simply equal to $\pi_{t}^{e}$. The reason the period $t$ optimality condition for the intermediate good price setting decision is not included in a time $t$ continuation equilibrium is that that equilibrium takes $p_{-i, t}^{e}$ as given.

By Definition 3, $c_{t}^{e}$ is a function of the state, $\left(h_{t-1}, \pi_{t}^{e}\right)$. So, we can write (4.4) as follows:

$$
x_{t}=\pi_{t}^{e}+(\gamma+\psi) \ln c_{t}^{e}\left(h_{t-1}, \pi_{t}^{e}\right) .
$$

In practice, it there is only a finite set of types of history, $\left(h_{t-1}, \pi_{t}^{e}\right)$. There are two types of $h_{t-1}$ : one in which the inflation monitoring range has never been violated; and the other in which it was violated at least once. The number of types of $\pi_{t}^{e}$ depends on the type of $h_{t-1}$. If there has been no violation of the inflation monitoring range in the past, then, there are four types of $\pi_{t}^{e}$ to consider: $\pi_{t}^{e}>\pi_{u}, \pi_{t}^{e} \in\left[\pi_{l}, \pi_{u}\right], \phi^{-1} R^{l}<\pi_{t}^{e}<\pi_{l}$ and $\pi_{t}^{e} \leq \phi^{-1} R^{l}$. If there has been a violation in the past, then there are two types of $\pi_{t}^{e}$ to consider: those for which the lower bound on the nominal rate of interest is binding and the others.

The object, $x_{t}$, in (4.6) is the (scaled and logged) price chosen by the $i^{\text {th }}$ firm, given its conjec- 
ture, $\pi_{t}^{e}$, and given $h_{t-1}$. Because the $i^{\text {th }}$ firm thinks (correctly) that everyone else behaves in the same way, the $x_{t}$ chosen by the $i^{t h}$ firm is also its conjecture about what the others do and, hence, maps into a conjecture about the aggregate price index. ${ }^{14}$ So a firm's conjecture that inflation will be $\pi_{t}^{e}$ leads, via a chain of reasoning captured by (4.6), to another conjecture about inflation, namely, $x_{t}$. We assume that a firm can only have one belief about a given variable. For this reason we suppose that a firm's belief is a conjecture that is a fixed point of (4.6):

Definition 4. Given history, $h_{t-1}$, the $i^{\text {th }}$ firm's belief about period $t$ inflation is a value of $\pi_{t}^{e}$ with the property that $x_{t}=\pi_{t}^{e}$ in (4.6).

Thus, we distinguish between a conjecture and a special kind of conjecture which we call a belief. Beliefs are the conjectures that occur in a competitive equilibrium. For example, we see from (2.16) that in a competitive equilibrium, $c_{t}=1$, so that $x_{t}=\pi_{t}^{e}$, according to (4.6). Conjectures that are not beliefs allow us to contemplate off-equilibrium paths. Studying why such conjectures are not equilibria provides the economic answer to why a particular off-equilibrium path is not an equilibrium.

\subsection{Strategy Equilibrium.}

Consider the following definition:

Definition 5. A strategy equilibrium is a competitive equilibrium (see Definition (1)) with the property that for each possible history $h_{t-1}$ : (i) there is a well defined continuation equilibrium corresponding to any value of $\pi_{t}^{e}$ and (ii) there exists a $\pi_{t}^{e}$ that is a fixed point of (4.4).

When $h_{t-1}$ is composed of the equilibrium $\left(a_{j}\right)_{j=0}^{t-1}$, then condition (i) considers one-period deviations from the equilibrium. Because we allow for arbitrary $h_{t-1}$ we also consider the possibility of multi-period deviations. Condition (i) is important for our purposes, since it is what allows us to think in an organized way about why certain off-equilibrium paths are not equilibria.

We give our equilibrium concept a different name from the one in Atkeson et al. (2010) only because the objects in their equilibrium are functions while in our case they are sequences. We call ours a strategy equilibrium because the intermediate good firms in our model select a belief based on how they think the economy would react if that belief were true.

\footnotetext{
${ }^{14}$ The object, $x_{t}$, is a scaled and logged price, $\log \left[p_{i t} /\left(P_{t-1} \bar{\mu}^{*}\right)\right]$. So, $P_{t}=P_{t-1} \bar{\mu}^{*} e^{x_{t}}$.
} 
Finally, consider the following definition:

Definition 6. A policy uniquely implements an equilibrium if the competitive equilibrium is unique and the equilibrium is a strategy equilibrium.

We now state the following result:

Proposition 3. The Taylor rule with the escape strategy uniquely implements the desired equilibrium.

Given that the equilibrium is unique (see Proposition 2) it remains only to show that the desired equilibrium satisfies (i) and (ii) in Definition 5. This requires evaluating the continuation equilibrium for all possible $\left(h_{t-1}, \pi_{t}^{e}\right)$, where all the possibilities are described after equation 4.6. The two sections below consider the continuation equilibria and best response function for two interesting possibilities. For the others, see Lemma 5 in Appendix B. ${ }^{15}$

\subsubsection{How is it that High Inflation is Ruled Out in Equilibrium?}

Here, we investigate why $\pi_{t}>\pi_{u}$ is impossible in a strategy equilibrium, when $h_{t-1}$ is a history in which the monitoring range has never been violated. We need to show that $\pi_{t}^{e}>\pi_{u}$ cannot be a fixed point of (4.6). To do this, we first derive an expression for consumption in the period $t$ continuation equilibrium.

Period $t+1$ is the first period of the constant money growth regime. According to Definition 2 the money growth rate, $\bar{\mu}$, is greater than unity, so that Lemma 1 implies that $c_{t+1}=1$ and $\bar{M}_{t+1}=P_{t+1}$. Dividing the latter by the binding (because $\pi_{t}^{e}>0$ ) cash constraint in period $t$, $\bar{M}_{t}=c_{t} P_{t}$, we obtain

$$
\bar{\mu}=\frac{\bar{\pi}_{t+1}}{c_{t}} .
$$

Substituting into the household's intertemporal Euler equation, (2.5),

$$
\left(c_{t}^{e}\right)^{-\gamma}=\beta \frac{\bar{R}_{t}}{c_{t}^{e} \bar{\mu}} .
$$

\footnotetext{
${ }^{15}$ Atkeson et al. (2010) describe two other models for which they obtain unique implementation with the escape clause. We discuss those models below.
} 
Because the inflation monitoring range has not been violated in the past, the Taylor rule, (2.2), is in operation in the current period. Substituting the Taylor rule into the latter equation and rearranging, we obtain, after taking logs,

$$
\ln c_{t}^{e}=\frac{\phi}{1-\gamma} \pi_{t}^{e}-\frac{\mu}{1-\gamma}
$$

Substituting the last expression into (4.4), we obtain:

$$
x_{t}=\left[1+\frac{(\gamma+\psi) \phi}{1-\gamma}\right] \pi_{t}^{e}-\frac{(\gamma+\psi) \mu}{1-\gamma}
$$

The value of $\pi_{t}^{e}$ such that $x_{t}=\pi_{t}^{e}$ is:

$$
\pi_{t}^{e}=\frac{\mu}{\phi}<\pi_{u}
$$

Since the fixed point of the mapping, (4.9), is unique and lies below $\pi_{u}$ it follows that there is no fixed point greater than $\pi_{u}$. After scaling and logging, (4.7) implies:

$$
\begin{aligned}
\pi_{t+1}^{e} & =\mu+\ln c_{t}^{e} \\
& =\frac{\phi}{1-\gamma} \pi_{t}^{e}-\frac{\gamma \mu}{1-\gamma}
\end{aligned}
$$

We summarize these results in the form of a lemma:

Lemma 3. Suppose $\pi_{t}^{e}>\pi_{u}$. Then,

$$
\ln c_{t}^{e}=\frac{\phi}{1-\gamma} \pi_{t}^{e}-\frac{\mu}{1-\gamma}, \quad \pi_{t+1}^{e}=\frac{\phi}{1-\gamma} \pi_{t}^{e}-\frac{\gamma \mu}{1-\gamma}
$$

and there is no fixed point of the best response function with $\pi_{t}>\pi_{u}$.

Our analysis allows us to explain why $\pi_{t}>\pi_{u}$ is not a competitive equilibrium. When an intermediate good firm contemplates the possibility that inflation will be high because the other firms are setting high prices (i.e., $\pi_{t}^{e}>\pi_{u}$ ), it understands that the current interest rate will be high because of the Taylor rule and next period's inflation will be low because of (4.10). With the real rate interest high, the firm believes aggregate consumption will be low, so that the demand for labor and the real wage will be low too. With low conjectured marginal cost, the firm would 
raise price by less than the amount implicit in the rise in $\pi_{t}^{e}$ (this is captured by the coefficient on $\pi_{t}^{e}$ in (4.9) being less than unity) ${ }^{16}$. Understanding that other firms think in the same way, the firm would not form a belief, $\pi_{t}^{e}>\pi_{u}$ in the first place. This is the economic reason why we cannot have a one-period violation of the inflation monitoring range, $\pi_{t}>\pi_{u}$, followed by no further deviations from equilibrium. For multi-period violations, see Appendix B.

Thus, we have an answer to the question, 'why can there be no hyperinflation?' If firms anticipated such a thing they would anticipate a Volcker-style recession with low marginal costs and they would choose not to set the high prices necessary for high inflation to occur. This explains the observations in the introduction where we claimed that the escape clause works like the Taylor principle.

\subsubsection{How is Moderate, but Not Desired, Inflation Ruled Out in Equilibrium?}

As in the previous section, consider a history, $h_{t-1}$, in which the monitoring range has never been violated. We now consider the case, $\pi_{t} \in\left[\pi_{l}, \pi_{u}\right]$ and explain why it is that $\pi_{t} \neq 0$ cannot be an equilibrium. Consider the following lemma:

Lemma 4. The only fixed point of the best response function, (4.4), for $\pi_{t}^{e} \in\left[\pi_{l}, \pi_{u}\right]$ is $\pi_{t}^{e}=0$.

Proof. Consider $\pi_{t}^{e} \in\left[\pi_{l}, \pi_{u}\right]$. To evaluate the right side of the best response function, (4.4), we need to compute the period $t$ afternoon continuation equilibrium. Consider the periods after $t$ first. According to (2), the unique competitive equilibrium under the Taylor rule with escape clause has the property, $\pi_{t+1}=0$ and $c_{t+1}=1$. We then obtain period $t$ consumption in the period $t$ afternoon continuation equilibrium by substituting into the period $t$ household intertemporal Euler equation, (2.5):

$$
\left(c_{t}^{e}\right)^{-\gamma}=\beta\left(c_{t+1}^{e}\right)^{-\gamma} \frac{\bar{R}_{t}}{\bar{\pi}_{t+1}}=\beta \frac{\bar{R}_{t}}{\bar{\mu}^{*}}=\left(\frac{\bar{\pi}_{t}}{\bar{\pi}^{*}}\right)^{\phi},
$$

where the last equality uses the Taylor rule, (2.2). The Taylor rule is in place in period $t$ because of our assumption that the escape clause has not been activated in the past. Substituting the log

\footnotetext{
${ }^{16}$ Recall from $(2.3)$ that $\gamma>1$
} 
of the latter expression into (4.4) and collecting terms, we obtain:

$$
x_{t}=\pi_{t}^{e}+(\gamma+\psi) \ln c_{t}^{e}=\left[1-\frac{\phi}{\gamma}(\gamma+\psi)\right] \pi_{t}^{e}
$$

The only fixed point for this expression is $\pi_{t}^{e}=0$. Thus, $\pi_{t}^{e} \neq 0$ is not a fixed point, so that the desired result is established.

The intuition here is similar to the intuition underlying Lemma 3. Suppose $\pi_{u} \geq \pi_{t}^{e}>0$. Because inflation is above the desired level, the nominal interest rate is also high because of the Taylor rule. At the same time, the rate of inflation in the next period is expected to be at its desired level so that the real interest rate is high. This creates a fall in output, discouraging firms from raising prices. Knowing this, firms will not form a belief, $\pi_{t}^{e}>0$. Now consider the case, $\pi_{l} \leq \pi_{t}^{e}<0$. In this case, the government would generate a boom in output, giving firms an incentive to raise prices with the consequence that such a belief is not an equilibrium.

The proof of Lemma 4 provides the economic reason why it is that if we have an equilibrium path with $\pi_{t} \in\left[\pi_{l}, \pi_{u}\right]$ for all $t$, there cannot be any deviations from the competitive equilibrium. The reason is essentially the same as in Section 4.3.1. When price setters contemplate the conjecture that $\pi_{t}>0$, they anticipate that monetary policy will create a high real rate of interest, which will slow down the economy and discourage firms from setting the high prices that $\pi_{t}>0$ requires. It is interesting to note how once again this resembles the operation of the Taylor principle. The escape clause is responsible for this response to $\pi_{t}>0$ because it is the reason that the unique continuation equilibrium has $\pi_{t+1}=0$ after a moderate inflation.

\section{$5 \quad$ Where did Cochrane (2011) Go Wrong?}

We have explored why it is that non-desired inflation paths fail to be equilibria when monetary policy is characterized by the Taylor rule with an escape clause. The reasons do not involve anyone doing something infeasible. In contrast, as explained in Section 3, Cochrane (2011) argues that the escape clause trims undesired equilibria by a commitment to do something infeasible in case an undesired equilibrium occurs. 
Why does Cochrane (2011) reach such a different conclusion than we do? The different conclusions may at first seem surprising, since in both cases a competitive equilibrium is characterized by the same two equations: the Fisher equation, (2.17), and the Taylor rule, (2.18) (see Proposition 1). This illustrates the danger of drawing inferences about off-equilibrium events from the equilibrium conditions alone. One must work with an equilibrium concept like the strategy equilibrium, which uses more information about the underlying economy than is revealed by the equilibrium conditions. As it happens, there is an important difference between our economy and Cochrane (2011)'s.

Cochrane (2011, p. 574) assumes that the underlying economy is an endowment economy. To see the effect of this assumption, note that our model economy effectively reduces to an endowment economy if we assume that households supply a fixed amount of labor inelastically. In this case, consumption takes on the same value if we are on the equilibrium path, or we are on the offequilibrium paths that are contemplated in a Strategy Equilibrium (see Definition 5). So, the household's intertemporal Euler equation, (2.5), reduces to the Fisher equation, (2.17), both on and off-equilibrium. It follows that period $t$ continuation equilibria simply do not exist when $\pi_{t}^{e} \neq 0$. Put differently, in the endowment economy version of our model, the government commits to do something infeasible (raise the real rate of interest) in case inflation is higher than desired. Thus, deviations from the equilibrium path are enforced by a threat to blow up the economy, just as Cochrane (2011) suggests.

It follows that the unique competitive equilibrium of the endowment economy version of our model is not a Strategy Equilibrium. But, Cochrane (2011) is wrong to extrapolate from the properties of his model to those of monetary models in which output is endogenous. In particular, his analysis offers no reason to think that the escape clause is an uninteresting way to rule out non-desired equilibria in the kinds of monetary models used in practice, such as the New Keynesian model.

\section{The Atkeson et al. (2010) Argument}

Atkeson et al. (2010) direct attention to a policy with, $\pi_{l}=\pi_{u}=0$, so that the monitoring range 
is a singleton composed just of the desired rate of inflation. Our model also supports their finding that the desired equilibrium is the unique equilibrium outcome under their policy. However, the first section below shows that this result is fragile and not robust to small trembles. In the second section below we explain why the fragility may have important welfare consequences.

Finally, in the introduction we expressed skepticism about Atkeson et al. (2010)'s suggestion that their policy reveals the Taylor principle is not a necessary part of good monetary policy. Under that policy, to keep the economy in the desired equilibrium, $\phi>1$ is not necessary since the escape clause (assuming no trembles) can do that job all by itself. It is true that in the context of the Taylor rule, the parameter setting, $\phi>1$, is often referred to as the Taylor Principle, and

in that sense Atkeson et al. (2010) are right. But, in Section 5 we showed that in our model the escape clause is a commitment to raise the interest rate when inflation is high as a strategy for keeping inflation close to its desired level. As discussed in the introduction, this is basically a description of the Taylor Principle. So, replacing a Taylor rule with $\phi>1$ with an escape clause is tantamount to replacing one way of implementing the Taylor Principle with another.

\subsection{Fragility of the Atkeson et al. (2010) Monetary Policy}

We consider the possibility that a tiny subset (mass) of firms make a tiny mistake implementing their price decision. When this happens, then inflation drops out of the monitoring range, triggering a regime shift in money policy towards constant money growth.

We illustrate these points here with the use of trembles. Suppose that people form their beliefs as they do in previous sections, without imagining the possibility of trembles. They choose their belief as a solution to a fixed point problem, as discussed in Section 4.2. However, when the time comes for firms to post their price, a small number make a small mistake (the firm manager's hand 'trembles' as he/she writes the price on the door). In particular, let $p_{t}^{e}$ denote the $i^{\text {th }}$ firms expectation of how other firms post their price for all $i \in[0,1]$ :

$$
p_{i, t}=\overbrace{p_{t}^{e}\left(c_{t}^{e}\right)^{\gamma+\psi}}^{\text {price in absence of tremble }} v_{i, t} .
$$


This value of $p_{t}^{e}$ has the fixed point property that, given the continuation equilibrium conditional on $p_{t}^{e}$, firms set the same price. Suppose there is a tremble in the form of the additional variable, $v_{i, t}$, on the right side of (6.1). That tremble is a unit mean random variable which is drawn independently by each firm. The distribution of $v_{i t}$ has two parameters, $J_{t}, \delta_{t} \in[0,1]$. With probability $1-J_{t}$, the $i^{\text {th }}$ firm does not tremble at all, so that $v_{i, t} \equiv 1$. With probability $J_{t}$ the $i^{\text {th }}$ firm draws $v_{i, t}$ from a uniform distribution with support, $\left[1-\delta_{t}, 1+\delta_{t}\right]$. We can allow both $J_{t}$ and $\delta_{t}$ to be arbitrarily close to zero so that the subset of firms that tremble is very small and those that do tremble, do so by a small amount.

According to (2.11), the actual price index will be determined as follows :

$$
\begin{aligned}
P_{t} & =\left[\int_{0}^{1}\left(p_{t}^{e}\left(c_{t}^{e}\right)^{\gamma+\psi} v_{i, t}\right)^{1-\varepsilon} d i\right]^{\frac{1}{1-\varepsilon}} \\
& =p_{t}^{e}\left(c_{t}^{e}\right)^{\gamma+\psi} \exp \left(\kappa_{t}\right)
\end{aligned}
$$

where

$$
\exp \left(\kappa_{t}\right)=\left[1-J_{t}+J_{t} \frac{\left(1+\delta_{t}\right)^{2-\varepsilon}-\left(1-\delta_{t}\right)^{2-\varepsilon}}{2 \delta_{t}(2-\varepsilon)}\right]^{\frac{1}{1-\varepsilon}}
$$

As expected,

$$
\kappa_{t} \rightarrow 0 \text { as } J_{t} \rightarrow 0 \text { for fixed } \delta_{t}, \quad \kappa_{t} \rightarrow 0 \text { as } \delta_{t} \rightarrow 0 \text { for fixed } J_{t}
$$

Divide both sides of (6.2) by $\bar{\mu}^{*} P_{t-1}$ and take logs, to obtain:

$$
\pi_{t}=\pi_{t}^{e}+(\gamma+\psi) \ln \left(c_{t}^{e}\right)+\kappa_{t}
$$

Suppose the economy has, up to the present time, not experienced a tremble and that it has been in the desired equilibrium. As a result, firms set $\pi_{t}^{e}=0, c_{t}^{e}=1$ and they believe (they think $\left.\kappa_{t}=0\right) \pi_{t}=\pi_{t}^{e}=0$. But, this is not what will actually occur, if $J_{t}, \delta_{t}>0$. In this case, the tremble pushes the economy to switch to the money growth regime because $\pi_{t}=\kappa_{t}>0$. 


\subsection{The Fragility has Real Consequences if there are High-Frequency Money Demand Shocks}

In the model as it is set up now, the regime shift does not matter from a welfare standpoint. The same desired equilibrium outcomes occur whether the economy is following the Taylor rule or the money growth rule. But, if we assume money demand shocks are realized in the afternoon, then there is a substantial loss in jumping from the Taylor rule to the money growth rule. The assumption that the money demand shocks are realized in the afternoon is a way to capture the notion that money demand shocks operate at a higher frequency than price changes. The model is a variant of the sticky price model in Christiano et al. (1997), where time $t$ prices are predetermined when time $t$ shocks are realized.

We introduce money demand shocks, $\nu_{t}$, by inserting them into the cash constraint:

$$
P_{t} c_{t} \leq m_{t} \nu_{t}
$$

We assume these shocks are iid, have unit mean and are drawn from a uniform distribution with continuous support. It is easy to show that under the Taylor rule, $l_{t}, c_{t}$ behave as they do in the desired equilibrium in the absence of money demand shocks. Under the Taylor rule, the money supply moves in such a way that consumption and employment are first-best and are insulated from the realizations of $\nu_{t}$. In the money growth regime, things are different. It is easy to see that in that equilibrium,

$$
l_{t}=c_{t}=\frac{\nu_{t}}{\left[E \nu_{t}^{\gamma+\psi}\right]^{\frac{1}{\gamma+\psi}}}
$$

A shift from the interest rate regime to the money growth regime, says due to trembles, would have a substantial negative welfare effect.

\section{Summary}

In the current workhorse model in macroeconomics, the New Keynesian model, it is common to focus on a locally unique equilibrium around the unique interior steady state. This equilibrium was 
referred to here as the 'desired equilibrium'. The analysis of the desired equilibrium has contributed to policy debates about a wide range of topics, from inflation targeting to the government spending multiplier, to how to deal with financial frictions. In addition, the properties of the desired equilibrium resemble, in some important ways, the dynamic properties of actual data. ${ }^{17}$ Yet, it is known that the model has other equilibria. At the very least, it has another, non-interior, steady state (BSGU). Moreover, analysis of simple models suggests there could be other equilibria as well.

This state of affairs represents a serious challenge, because without a convincing way to rule out the other equilibria the model does not, in fact, pin down output, employment, inflation, etc. Various rationales have been offered for focussing on the desired equilibrium. Here, we analyze the escape clause strategy proposed by BSGU and Christiano and Rostagno (2001).

The standard analysis is validated if we suppose that the government commits to a regime switch to some other policy that returns inflation to its desired level in the event that a nondesired equilibrium appears to be forming. There are at least three ways to understand why this might be a natural policy. First, governments in fact do switch to very different policies when things appear to be going seriously awry. The recent recession and financial crisis in the US is one example. So, the notion that a commitment to a regime switch might coordinate expectations on a desired equilibrium does not seem far-fetched. Second, the non-desired equilibria in the stand-in for the New Keynesian model we consider here requires government complicity. A commitment to stop accommodating non-desired equilibria in case they occur seems like an obvious remedy.

We study how the escape clause rules out non-desired equilibria. To do this, we use the equilibrium concept that allows for out-of-equilibrium behavior suggested in Bassetto (2005) and Atkeson et al. (2010). Our model allow us to address critics of the escape policy studied in this paper. In that policy, the government sets an inflation monitoring range that is relatively wide, and then commits to switch to a money growth regime in case the economy jumps outside the monitoring range. We preserve the stabilizing properties of the Taylor Principle by keeping a high coefficient on inflation in the Taylor rule. We show that the escape clause rules out all non-desired

\footnotetext{
${ }^{17}$ For a recent summary of the role in data and policy analysis of the New Keynesian model that focuses on the locally unique equilibrium around steady state, see Christiano et al. (2018b)
} 
equilibria by what one might call a Global Taylor Principle. If the economy were to move away from the desired equilibrium, say by a rise in inflation above the desired level, then the presence of the escape clause would cause the real rate of interest to rise. The ensuing recession would discourage individual firms from setting the high prices that the high inflation requires. As a result, expectations of inflation above target cannot occur in the first place. We show that the Global Taylor Principle does for out-of-equilibrium inflation what the Taylor Principle does for actual inflation in a stochastic version of the desired equilibrium. ${ }^{18}$

Cochrane (2011) argues that the equilibrium uniqueness accomplished by the escape clause is not due to the escape clause per se. He concludes that it is instead due to the fact that the government commits to do something infeasible in the event that a non-desired equilibrium forms. We agree that if this were the last word on the escape clause, it would render that proposal absurd since the impact on private sector expectations of such a commitment would be completely unpredictable. However, we show that Cochrane (2011)'s conclusion is simply an artifact of his endowment economy assumption, since it is infeasible for the government to create a recession. So, Cochrane (2011)'s findings provide no information about how the escape clause works in an economy like the New Keynesian model, where production is endogenous. We suspect that in any model with a monetary transmission that resembles the Taylor Principle, the escape clause will exclude equilibria that are outside the neighborhood of the desired equilibrium.

We also push back against the argument in Atkeson et al. (2010) that the Taylor Principle is unnecessary to achieve a unique equilibrium. They reach this conclusion by studying a version of the escape clause in which the inflation monitoring range is reduced to a singleton that includes only the desired level of inflation. In this case the usual Taylor Principle, having a high coefficient on inflation in the Taylor rule, plays no role in stabilizing the economy. Everything is accomplished by the escape clause itself. According to our analysis, their conclusion is misleading, because in our model the escape clause works exactly like an out-of-equilibrium version of the Taylor Principle (the Global Taylor Principle). Moreover, their policy is not of practical relevance because we show it is not robust to tiny errors in price setting made by a tiny fraction price setters (trembles). In

\footnotetext{
${ }^{18}$ How the Taylor Principle works in stochastic models is well understood. For completeness, we include a brief summary of the results in footnote 7 .
} 
the presence of money demand shocks, trembles would set off the escape clause by accident - not because a non-desired equilibrium is forming - and the economy would switch to a money growth rule. The money growth rule is welfare inferior in the presence of money demand shocks, in our model. 


\section{A Proofs}

\section{A.1 Proposition 1}

Proof. For each $\pi_{0}>0$, there is a sequence of inflation, $\left\{\pi_{t}\right\}_{t=1}^{\infty}$, that satisfies (2.18) in which inflation explodes to $\infty$. The interest rate associated with such a sequence is greater than unity for each $t$, so that (2.6) implies the cash constraint is binding and $m_{T} / P_{T}=c_{T}=1$, or all $T$ by $(2.16)$. Trivially, the transversality condition, (2.21), is satisfied. Similarly, a sequence that satisfies (2.20) with $\pi_{0}<0$ converges to $\ln \left(\beta / \bar{\pi}^{*}\right)$, so that actual gross inflation converges to $\beta$. To see that this sequence satisfies $(2.21)$ note that $\pi_{t}$ converges in finite time to its fixed point, $\pi_{t}=\ln \left(\beta / \bar{\pi}^{*}\right)$. Suppose convergence occurs at $t=\bar{t} \geq 0$. Then, for $T>\bar{t}, R_{T}=1$ so $(2.5)$ implies $P_{T}=\beta^{T-\bar{t}} P_{\bar{t}}$. Setting $m_{T}=\beta^{T-\bar{t}} m_{\bar{t}}$ for all $T>\bar{t}$ so that $m_{T} / P_{T}=m_{\bar{t}} / P_{\bar{t}}$, a constant $\geq c_{T}$ for all $T>\bar{t}$, we have that the cash constraint, (2.6), is satisfied and

$$
\frac{m_{T}}{P_{T}}=\frac{m_{\bar{t}}}{P_{\bar{t}}} \beta^{T} \rightarrow 0
$$

so that (2.21) is satisfied too. The uniqueness result is stated in Proposition 1.

\section{A.2 Lemma 1}

Proof. First, we show that in any equilibrium, $\bar{R}_{t}>1$ for all $t$. Recall the Fisher equation, (2.17), and the complementary slackness condition associated with the cash constraint, $(2.6), t \geq 0$ :

$$
\bar{\pi}_{t+1}=\beta \bar{R}_{t} \text { (Fisher) }, \quad 0=\overbrace{\left(\bar{R}_{t}-1\right)}^{\geq 0,} \overbrace{\left(\bar{M}_{t}-P_{t} y\right)}^{\geq 0, \text { cash constraint }} .
$$

Suppose, to the contrary, that $\bar{R}_{t}=1$ for some $t$. It follows that $\bar{R}_{t+1}=1$. To see this, note that $\bar{\pi}_{t+1}=\beta$ by the Fisher equation so that $P_{t+1}<P_{t}$. At the same time, $\bar{M}_{t+1} \geq \bar{M}_{t}$ because of our assumption, $\bar{\mu} \geq 1$. These two observations, together with $\bar{M}_{t} \geq P_{t} y$ imply that $\bar{M}_{t+1}>P_{t+1} y$. The complementary slackness condition then implies that $\bar{R}_{t+1}=1$.

By induction, we conclude that $\bar{R}_{t}=1$ implies $\bar{R}_{t+s}=1$ and $\bar{\pi}_{t+s+1}=\beta$ for $s \geq 0$. But, this 
contradicts the hypothesis of equilibrium because the transversality condition is violated. To see this, note that for any fixed $t$,

$$
\lim _{T \rightarrow \infty} \beta^{T} \frac{\bar{M}_{T}}{P_{T}}=\lim _{T \rightarrow \infty} \underbrace{\frac{\beta^{T-t}}{P_{T} / P_{t}}}_{=1} \beta^{t} \frac{\bar{M}_{T}}{P_{t}}=\frac{\beta^{t}}{P_{t}} \lim _{T \rightarrow \infty} \bar{M}_{T}>0 .
$$

Thus, we conclude that in any equilibrium, $\bar{R}_{t}>1$ for all $t \geq 0$. To suppose otherwise entails a contradiction.

Next, we show that with $\bar{R}_{t}>1$, for all $t \geq 0$, the equilibrium conditions uniquely determine all variables. The cash constraint binds, $\bar{M}_{t}-P_{t} y=0$, for each $t \geq 0$, so

$$
\bar{\pi}_{t+1}=\bar{\mu} .
$$

Also, the Fisher equation implies

$$
\bar{R}_{t}=\beta^{-1} \bar{\pi}_{t+1}=\beta^{-1} \bar{\mu}>1 \text {. }
$$

The cash constraint and $\bar{R}_{0}>1$ implies

$$
P_{0} y=\bar{M}_{0} \Longrightarrow P_{0}=\frac{\bar{M}_{-1}}{y} \frac{\bar{M}_{0}}{\bar{M}_{-1}}=\frac{\bar{M}_{-1}}{y} \bar{\mu} .
$$

We have established: Suppose $\bar{M}_{-1}$ is given and monetary policy sets $\bar{M}_{t}=\bar{\mu} \bar{M}_{t-1}$ for $t \geq 0$, where $\bar{\mu} \geq 1$. There exists a unique equilibrium with the properties:

$$
\bar{R}_{t}=\beta^{-1} \bar{\mu}>1, \quad \bar{\pi}_{t+1}=\bar{\mu}, \quad \text { for } \quad t \geq 0, \quad \text { and } \quad P_{0}=\bar{M}_{-1} \frac{\bar{\mu}}{y},
$$

which is the result sought. 


\section{A.3 Proposition 2}

Proof. Suppose, to the contrary, that $\pi_{0} \neq 0$. From Lemma 2 equilibrium has the property that the monitoring range is never violated, i.e., $\pi_{t} \in\left[\pi_{l}, \pi_{u}\right]$. The Taylor rule, (2.18), the Fisher equation, (2.17), and $\pi_{l}>\frac{R^{l}}{\phi}$, implies that in equilibrium:

$$
\pi_{t+1}=\max \left\{R^{l}, \phi \pi_{t}\right\}=\phi \pi_{t}
$$

Evidently, $\pi_{0} \neq 0$ implies $\pi_{t} \notin\left[\pi_{l}, \pi_{u}\right]$ for some $t$, given $\phi>1$. This contradicts Lemma 2 . We conclude that $\pi_{0}=0$, establishing the result.

\section{B Existence of a continuation equilibrium for arbitrary his- tory}

To show that the unique competitive equilibrium is a strategy equilibrium, we need to establish that there exists a continuation equilibrium for arbitrary history. In the paper, we have shown that a continuation equilibrium exists if the Taylor rule is operative at date $t$ and the inflation rate is weakly greater than $\pi_{l}$. (See Lemma 3 and Lemma 4). We cover the other cases in Lemma 5.

Lemma 5. For any $\left(h_{t-1}, \pi_{t}^{e}\right)$, there exists a continuation equilibrium. In particular;

1. If the Taylor rule is operative at $t$ and $\phi^{-1} R_{l}<\pi_{t}^{e}<\pi_{l},{ }^{19}$ the continuation consumption, employment and money demand at date $t$ are the same Lemma 3.

2. If the Taylor rule is operative at $t$ and $\pi_{t}^{e} \leq \phi^{-1} R_{l},{ }^{20}$ the continuation consumption, employment and money demand at date $t$ are

$$
\begin{aligned}
\ln c_{t} & =\ln l_{t}=\frac{R_{l}-\mu}{1-\gamma} \\
\mu_{t} & =\pi_{t}^{e}+\ln c_{t} .
\end{aligned}
$$

Notice that the cash constraint at date $t$ is binding.

\footnotetext{
${ }^{19}$ The existence of a continuation equilibrium for $\pi_{t}^{e}>\phi^{-1} R_{l}$ is already established in Lemma 3 and 4 .

${ }^{20}$ The existence of a continuation equilibrium for $\pi_{t}^{e}>\phi^{-1} R_{l}$ is already established in Lemma 3 and 4 .
} 
3. If the money growth rule is operative and $\pi_{t}^{e} \in D\left(h_{t-1}\right)$, where

$$
D\left(h_{t-1}\right)=\left\{\pi_{t}^{e}:(1-\gamma)\left[\mu+\ln \frac{M_{t-1}}{P_{t-1}}-\pi_{t}^{e}\right]+\mu>R_{l}\right\}
$$

then the continuation consumption, employment and interest rate at date $t$ are

$$
\begin{aligned}
\ln c_{t} & =\ln l_{t}=\mu+\ln \frac{M_{t-1}}{P_{t-1}}-\pi_{t}^{e} \\
R_{t} & =(1-\gamma) \ln c_{t}+\mu .
\end{aligned}
$$

4. If the money growth rule is operative and $\pi_{t} \notin D\left(h_{t-1}\right)$, then

$$
\begin{aligned}
\ln c_{t} & =\ln l_{t}=-\frac{1}{\gamma}\left(R_{l}-\left[\mu+\left(\mu-\pi_{t}^{e}\right)+\ln \frac{M_{t-1}}{P_{t-1}}\right]\right) \\
R_{t} & =R_{l} .
\end{aligned}
$$

Notice that we have already established existence of a continuation equilibrium if $\pi_{t}^{e} \geq \pi_{l}$ and the Taylor rule is operative at time $t$.

Proof. We construct a continuation equilibrium for each $\left(h_{t-1}, \pi_{t}^{e}\right)$. From We know that there exists a continuation equilibrium after $t+1$ from Lemma 1 and Proposition 2. So, we need to construct date- $t$ variables so that all the date- $t$ afternoon equilibrium conditions, (2.5), (2.6), and are satisfied.

It is easy to show that the proof in Lemma 3 is applied for showing case (1). Thus we omit the proof here and left it for readers. Consider case (2); we consider a history in which the Taylor rule is operative at date $t$ and $\pi_{t}^{e} \leq \phi^{-1} R_{l}$. Suppose that $\pi_{t}^{e} \leq \phi^{-1} R_{l}$. The monitoring range is violated so that the continuation equilibrium from $t+1$ is unique, and consumption and price are

$$
c_{t+1}=1, \quad \pi_{t+1}=\mu+\ln \frac{M_{t}}{P_{t}}
$$

By construction of (B.2), the cash constraint (2.6) is satisfied as equality. binding cash constraint, 
$m_{t}=P_{t} c_{t}$. Also, the Euler equation (2.5) is also satisfied. To show it,

$$
\begin{aligned}
& -\gamma \underbrace{\ln c_{t+1}}_{=0}+\underbrace{R_{t}}_{=R_{l}}-\underbrace{\pi_{t+1}}_{=\mu+\ln c_{t}}+\gamma \ln c_{t} \\
= & R_{l}-\left(\mu+\ln c_{t}\right)+\gamma \ln c_{t} \\
= & R_{l}-\mu+\underbrace{(\gamma-1) \ln c_{t}}_{=\mu-R_{l}}=0 .
\end{aligned}
$$

Therefore all the afternoon equilibrium conditions are satisfied by (B.1) and (B.2).

Second, consider case (3). Again we need to show that the Euler equation (2.5) and cash constraint (2.6) are satisfied with (B.4) and (B.5) conditional on the continuation equilibrium from $t+1$. In particular, consumption and inflation rate is

$$
c_{t+1}=1, \quad \pi_{t+1}=\mu+\ln \frac{M_{t}}{P_{t}} .
$$

Cash constraint is trivially satisfied by construction. Put differently, the real balance $M_{t} / P_{t}$ is equal to consumption $c_{t}$. The Euler equation is satisfied since

$$
\begin{gathered}
-\gamma \underbrace{\ln c_{t+1}}_{=0}+\underbrace{R_{t}}_{=(1-\gamma) \ln c_{t}+\mu}-\underbrace{\pi_{t+1}}_{=\mu+\ln c_{t}}+\gamma \ln c_{t} \\
=(1-\gamma) \ln c_{t}+\mu-\mu-\ln c_{t}+\gamma \ln c_{t}=0 .
\end{gathered}
$$

Also, notice that the nominal rate is greater than the lower bound $R_{l}$ :

$$
R_{t}=(1-\gamma)\left[\mu+\ln \frac{M_{t-1}}{P_{t-1}}-\pi_{t}^{e}\right]+\mu>R_{l}
$$

since $\pi_{t}^{e} \in D\left(h_{t-1}\right)$.

Finally consider case (4). Note that in this case the interest rate implied by (B.10) is weakly less than $R_{l}$. Again from $t+1$, there exists a continuation equilibrium with

$$
c_{t+1}=1, \quad \pi_{t+1}=\mu+\ln \frac{M_{t}}{P_{t}}=\mu+\left(\mu-\pi_{t}^{e}\right)+\ln \frac{M_{t-1}}{P_{t-1}} .
$$


For the last equation, we use the fact that the monetary policy at date $h$ is a constant money growth policy. Using (B.6), (B.7), and (B.11), we can show that the Euler equation is satisfied:

$$
\begin{aligned}
& -\gamma \underbrace{\ln c_{t+1}}_{=0}+\underbrace{R_{t}}_{=R_{l}}-\underbrace{\pi_{t+1}}_{=\mu+\left(\mu-\pi_{t}^{e}\right)+\ln \frac{M_{t-1}}{P_{t-1}}}+\gamma \ln c_{t} \\
= & R_{l}-\left[\mu+\left(\mu-\pi_{t}^{e}\right)+\ln \frac{M_{t-1}}{P_{t-1}}\right]-\left(R_{l}-\left[\mu+\left(\mu-\pi_{t}^{e}\right)+\ln \frac{M_{t-1}}{P_{t-1}}\right]\right)=0 .
\end{aligned}
$$

The cash constraint is also satisfied. First notice that

$$
M_{t} \geq P_{t} c_{t} \Longleftrightarrow \mu-\pi_{t}^{e}+\ln \frac{M_{t-1}}{P_{t-1}} \geq \ln c_{t} .
$$

It is easy to show that

$$
\begin{aligned}
& \mu-\pi_{t}^{e}+\ln \frac{M_{t-1}}{P_{t-1}}-\ln c_{t} \\
= & \left(\mu-\pi_{t}^{e}\right)+\ln \frac{M_{t-1}}{P_{t-1}}+\frac{1}{\gamma}\left(R_{l}-\left[\mu+\left(\mu-\pi_{t}^{e}\right)+\ln \frac{M_{t-1}}{P_{t-1}}\right]\right) \\
= & \frac{1}{\gamma}\left\{\left(R_{l}-\mu\right)-(1-\gamma)\left[\left(\mu-\pi_{t}^{e}\right)+\ln \frac{M_{t-1}}{P_{t-1}}\right]\right\} .
\end{aligned}
$$

Since $\pi_{t}^{e} \notin D\left(h_{t-1}\right)$, we have

$$
\begin{gathered}
R_{l} \geq(1-\gamma)\left[\mu+\ln \frac{M_{t-1}}{P_{t-1}}-\pi_{t}^{e}\right]+\mu \\
\Longleftrightarrow R_{l}-\mu-(1-\gamma)\left[\mu+\ln \frac{M_{t-1}}{P_{t-1}}-\pi_{t}^{e}\right] \geq 0 .
\end{gathered}
$$

Combining (B.13) with (B.12), we get

$$
\mu-\pi_{t}^{e}+\ln \frac{M_{t-1}}{P_{t-1}}-\ln c_{t} \geq 0
$$

which is equivalent to cash constraint at date $t$. Thus (B.6) and (B.7) satisfy the date- $t$ afternoon equilibrium conditions from $\left(h_{t-1}, \pi_{t}^{e}\right)$. 


\section{References}

Albanesi, Stefania, Varadarajan V. Chari, and Lawrence J. Christiano, "How Severe Is the Time-Inconsistency Problem in Monetary Policy?," Federal Reserve Bank of Minneapolis Quarterly Review, 2003, 27 (3), 17-33.

Atkeson, Andrew, Varadarajan V. Chari, and Patrick J. Kehoe, "Sophisticated Monetary Policies," The Quarterly Journal of Economics, 2010, (February), 47-89.

Bassetto, Marco, "Equilibrium and government commitment," Journal of Economic Theory, 2005, $124(1), 79-105$.

Benhabib, Jess, Stephanie Schmitt-Grohé, and Martin Uribe, "Monetary policy and multiple equilibria," American Economic Review, 2001, 74 (2), 165-170.

_, _, and _, "The Perils of Taylor rules," Journal of Economic Theory, 2001, 96 (1-2), 40-69.

_ , _, and _ , "Avoiding liquidity traps," Journal of Political Economy, 2002, 110 (3), 535-563.

_, _, and _ , "Chaotic interest-rate rules," American Economic Review, 2002, 92 (2), 72-78.

Chari, V. V. and Patrick J. Kehoe, "Sustainable Plans," Journal of Political Economy, 1990, $98(4), 783-802$.

Christiano, Lawrence J., "Comment on Acemoglu, Akcigit and Kerr," Macroeconomics Annual, 2016 .

Christiano, Lawrence J and Massimo Rostagno, "Money Growth Monitoring and The Taylor Rule," National Bureau of Economic Research Working Paper 8539, 2001.

Christiano, Lawrence J. and Yuta Takahashi, "Appendix: Deviant Behavior and Macroeconomics," 2018.

_, Cosmin L Ilut, Roberto Motto, and Massimo Rostagno, "Monetary Policy and Stock Market Booms," Proceedings of the Conference in Jackson Hole, "Macroeconomic Challenges: The Decade Ahead", 2010. 
Christiano, Lawrence J, Martin S. Eichenbaum, and Benjamin K Johannsen, "Does the New Keynesian Model Have a Uniqueness Problem?," National Bureau of Economic Research Working Paper 24612, 2018.

Christiano, Lawrence J., Martin S. Eichenbaum, and Charles L. Evans, "Sticky Price and Limited Participation Models of Money: A Comparison," European Economic Review, 1997, $41(6), 1201-1249$.

_ , _, and Mathias Trabandt, "On DSGE Models," Journal of Economic Perspectives, August 2018, 32 (3), 113-40.

_ , Mathias Trabandt, and Karl Walentin, "DSGE Models for Monetary Policy Analysis," Handbook of Monetary Economics, 2010, 3, 285-367.

Cochrane, John H., "Determinacy and Identification with Taylor Rules," Journal of Political Economy, 2011, 119 (3), 565-615.

Obstfeld, Maurice and Kenneth Rogoff, "Speculative Hyperinflations in Maximizing Models: Can We Rule Them Out?," Journal of Political Economy, 1983, 91 (4), 675-687.

_ and _ , "Revisiting Speculative Hyperinflations in Monetary Models," Centre for Economic Policy Research working paper, 2017.

Taylor, John B., "Policy Rules as a Means to a More Effective Monetary Policy," Bank of Japan Monetary and Economic Studies, July 1996, 14 (1), 28-39.

Taylor, John B, "A Historical Analysis of Monetary Policy Rules," in "Monetary policy rules," University of Chicago Press, 1999, pp. 319-348.

Woodford, Michael, Interest and Prices: Foundations of a Theory of Monetary Policy, Princeton University Press, 2003. 